\title{
Exploring Digital Storytelling on Cultural Issues at the English Lessons in Multilingual Classrooms
}

\author{
R. F Zhussupova \\ Assoc. Prof. Department of Philology, Eurasian National University, Astana, Kazakhstan
}

\begin{abstract}
For centuries rendering stories have been the most powerful medium for transmitting cultural heritage to next generations because stories are initially used for the purpose of education. In the past two decades, the dynamic emerging of technological innovations has given fresh start to new forms of culture and language teaching that is completely different from print-based source. Also, computers and digital have become a breeding ground for massive variety of new methodological approaches and pedagogical techniques. Multicultural education is considered to be a good opportunity for our country to integrate young generation into the world economy and global society, but still we come across some difficulties. This research aims at giving an analysis about the implementation of digital storytelling into multicultural education during learning English classes on topic entitled " " for the 1st year students which took place 7 weeks. The present questionnaire-based study examines the outcomes of digital storytelling procedures at the Eurasian National University. The study was performed through theoretical study of the phenomenon, observing, monitoring, focus groups' interviews, and testing. Moreover, the present study was an attempt to investigate the effect of creating and perceiving storytelling on students' cultural awareness. Data elaboration and statistical analysis were performed. The results of the study showed that the implementation of traditional storytelling with well-designed, attractive and demanding regarding highranked cognitive activities integrated with new technology had fulfilled its true instructional potential making students' minds more creative and provided the perfect environment for language and culture teaching.
\end{abstract}

Keywords: Foreign language learning, English teaching, Digital storytelling

\section{Introduction}

Foreign language learning comprises of several components, including grammatical competence, communicative competence, language proficiency, as well as culture competence. Undoubtedly, cultural awareness an integral part of foreign language learning and incorporation it in curriculum is a goal for foreign language teachers. The role of English language knowledge in Kazakhstan is also vital. The topicality of the research is determined in the need of extensive utilizing of media and modern technological tools in language teaching and their use provides great opportunities for the implementation of the most important didactic principles - the principle of visualization and individualization. Furthermore, the aim of the research is to consider the peculiarities of digital storytelling (DSt) and prove experimentally the effectiveness of the integration of digital stories on cultural topics into English language classroom. Hence according to the aim, we have allocated the following objectives: to consider the theoretical basis for the use of digital stories; to analyze the possibility of implementation of digital stories in Kazakhstani school setting and develop and probe lesson plans comprising digital stories; to prove experimentally the effectiveness of using digital stories in the English lessons. Also, selection of topics proved the efficiency of digital stories in rising cultural awareness. This study introduces development both language skills and technical means because storytelling maintains creativeness, sense of authorship, skills to be careful listeners, and to develop cultural interests in learning a language.

\section{Literature Review}

Literature defines that language teachers should be the mediators between learners and culture of both language foreign and native. In 2006 Barry Tomalin signifies that "cultural awareness training is changing". Language teachers are responsible for providing the cultural information that compiles the language. However, in practice, many foreign language teachers focus on more on grammatical competence and ignore teaching the target culture. Besides awareness of cultural 
values, beliefs, history and behavior does not particularly force the learner to adopt foreign culture norms. They exist to purify the self in order that it takes a more global and less self-centered form. Kramsch (2001) defines culture as "outdoor gardens with no meaning in themselves unless they are related to and contrasted with indoor apartments and dwellings". Moreover Michael Byram (2002) points out key qualities of a being successfully person across cultures.

Using new digital technology at the English lessons particularly educational digital stories, due to its easy production and the possibility of immediate web publishing, implies a fast exchange of information and access to the final products, thus facilitating in a way not previously possible a user-friendly tool that may serve the purpose of exchanging students' ideas and points of view on the same topic; with no borders regarding, distance, time, or accessibility. Otherwise, cited Brenner K. (2014), digital story is a perfect tool that can be used to help students overcome the cultural shock in the process of second language learning. Digital stories may assist students integrate into target culture and life in general, both at academic and sociocultural levels. In 2014 Dudeney, G., Hockly, N., and Pegrum, M. explore new digital literacies in detail, offering a range of practical ideas of how they can be developed in the English language classroom. They determine taxonomy of the new literacies by breaking them down into four main areas: those with a focus on language, on connections, on information, and on (re)design. Combine the old age tradition of storytelling with the latest technology and the result is a compelling tool that motivates students to read more and write better. The technique is called digital storytelling (DSt). It is a good way to engage students in both traditional and innovative way of telling a story. There exists the opinion that DSt perfectly combines the art of telling stories with a variety of digital multimedia, such as images, audio, and video (Brenner K., 2014). DSt includes the telling of personal tales, the recounting of historical events, or as a means to inform or instruct on a particular topic. Digital stories can also foster a sense of ownership in learners, let learners have a deeper understanding of the text and facilitate learners to have a longer retention rate of the text. Moreover it is used to improve learners' writing skills, learning in the content, facilitate collaborative activities, promote in-class discussion, motivate learners to learn critical thinking skills, and foster understanding of complex ideas. Thus, DSt is an excellent application in the foreign context that improves the traditional storytelling techniques, basic word processing programs and social software by incorporating multimedia and multi literacies resulting in increased levels of engagement, analysis and critical thinking skills. It has been shown to increase learning engagement and Technology tools that support DSt are readily available and much easier to use today than they were in years past.

\section{Stages of Implementation of Digital Storytelling in Higher Education and Steps Followed}

\section{Participants' profile}

Methodological basis of the research are integrated general and specific methods, including observation, study and synthesis of experience, questioning, experiment and critical analysis of scientific and methodical literature on the problem of the research and statistical analysis. Firstly we learned information on fundamentals of digital storytelling: its history of development, ways of implementation and structural basis. Also, the significance of cross-cultural awareness was considered. The practical part of the research was based on designing lessons during 7 weeks and their realization in Kazakhstani English language classroom and then was presented an analysis of the experiment from the three sides: to the impact on four language skills development, cultural awareness and average academic performance.

Our research was held in the Eurasian National University with the 1st year students of the speciality "Foreign Language: Two Foreign Languages" during 7 weeks. There were 3 groups totally 60 students including 18 males and 42 females. Each group is divided into two subgroups due to the academic aptitude: subgroup "A" and subgroup "B", 10 students in each. Subgroup "A" overall has the same marks and level of knowledge as subgroup "B". The research was held in group "B" which called experimental with implementing DSt with cultural aspects while group " $A$ " has a traditional teaching approach. Students are quite united; they respect and value each other. The academic proficiency of the whole group is high enough. There is no evident leader in the class. However, there are a couple of girls, who eagerly arrange all class activities and keep the students united. They are the most responsible persons who are ready to help with any arrangement. Overall the students are well-mannered. They do not unitize obscene language, at least, in teacher's presence. At the lessons the part of the group is active and loud, another part is always rest are silent. Teacher has to make effort to arouse them from the indifference. The national structure is following: Kazakhs -33 , Ukrainians -6 , Russians -10 , Korean -3 , Azerbaijani - 2, Tatar-3, German - 3.

Subject-matter of texts and assignments meet the students' needs and interests in compliance with claimed age. Great attention is paid to forming of such integral skills as: conducting discussions, debates and disputes, work in a small group, 
conflict resolution, etc. The major drawback is the deficiency of audio-visual media. The teacher has to select appropriate audio material. Majority of students have B1 level of English proficiency.

\section{Experiment Procedures}

The initial test was elaborated to check four language skills acquisition consisting of 4 sections and has a purpose of analyzing such skills as reading, writing, speaking and listening. The checking is conducted on two academic hours, first hour for listening, reading and writing and second one for speaking. The content of the test is depicted in Table 1.

Figire 1. Students' four-skills acquisition average performance

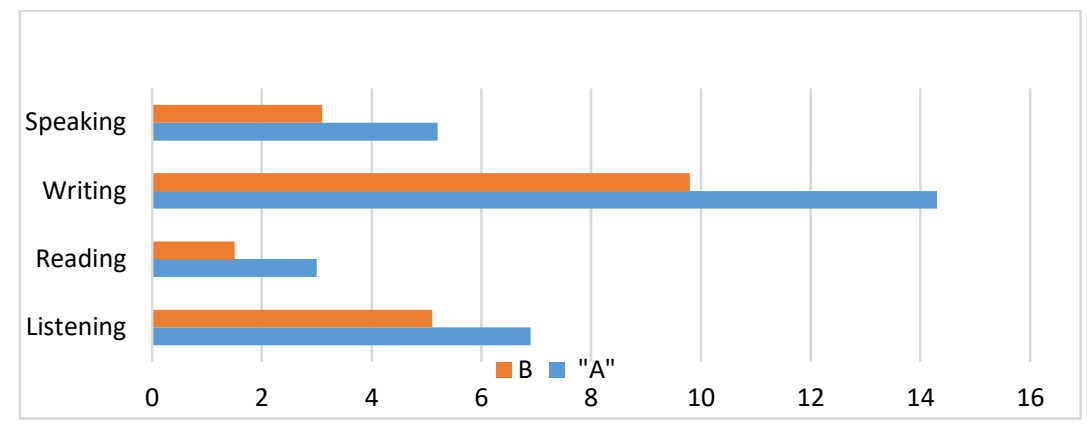

The control group is a subgroup "A", as the subgroups have separated lessons from the rest of the experiment, their result would not be affected by during experiment. An experimental group is the subgroup " $\mathrm{B}$ ". The experimental procedure is performed in their classrooms. The group is chosen, because it has lower results according to both language skills assessment and traditional marks criteria. Either positive or negative result would be more evidential in this subgroup.

The purpose of the digital story project is four-fold: to improve language proficiency competencies and cultural awareness; to maintain collaboration; to develop computer literacy; to build self-confidence.

The main tool for the study is Windows Movie Maker because it can be used offline and it build-in the Windows operation system for creating digital stories out of still images, video, and audio. It also can be used for trimming video, cropping images and to convert and overlay sounds and audio. The addition tools are the students' smartphones. They were used for internet browsing, searching data and appropriate material. Also, smartphones substitute photo and video camera and audio recorder. Implementing digital stories into the classroom setting is a long process demanding several preparatory steps. Digital storytelling is a kind of tool which teacher cannot bring into the classroom and start to use it at once. First of all it requires background knowledge in the sphere of modern technology, multimedia and a proper level of computer literacy. Students should be prepared to use internet sources and application for creating their own stories. Therefore, the plan of the research contains essential pre-production process which allows student to increase their literacy in the sphere of using technical equipment. Moreover, student should be acquainted with the technique of digital storytelling and its purposes, aims and procedure of creating.

This practical approbation continued for 1 whole term and according to the curriculum EFL target culture contains oriented elective course. The project was held in the course of elective lessons in order to embrace both cultural and technological elements without distortion of the curriculum. The digital storytelling unit plan comprises 7 Lessons for 2 academic hours each. The material is presented as a series of workshops in the experimental subgroup and as traditional lessons in the control subgroup. The cultural element in control subgroups was presented with the use of video, audio and reading materials.

With our desire to engage students in modern literacy practices was created a digital storytelling lesson plan hinged upon the assumption that students do not possess prior knowledge and skills regarding storytelling, figurative language, visual literacy, and computer technical skills. Considering that not all students in a classroom possess such knowledge, we created a plan converging all steps of implementing digital storytelling into classroom smoothly. Our plan is based on the experience of such scholars as Miller (2009) and Galac (2011). 


\section{Digital Storytelling Lesson Plan:}

Lesson 1 - Introduction to Digital Storytelling

\section{Objectives:}

To define digital storytelling

To explore what makes an effective digital story

\section{Lesson 2 - The Idea / Point of View}

\section{Objectives:}

To explore the digital storytelling process

To brainstorming ideas for digital story

To write a plan

\section{Lesson 3 - Background Information / Storyboard}

\section{Objectives:}

To write a script

To create storyboard

To research topic and find informational content

\section{Lesson 4 - Collecting Artifacts}

\section{Objectives:}

To revise a narrative script

To select appropriate images and sounds

\section{Lesson 5 - Assembly / Pacing}

Objectives:

To learn about digital storytelling software

To assemble the pieces of the multimodal digital story

To record narration

\section{Lesson 6 - Editing and feedback}

\section{Objectives:}

To finalize the story

To receive feedback and make final edits

To practice presentation

\section{Lesson 7 - Share, Feedback, Reflect}

\section{Objectives:}

To present the digital stories to peers, family, and community 
To reflect on the learning process

The unit comprises seven lesson plans that completely disclose the technique of DSt giving students an opportunity to create and present their stories with cultural issues.

\section{Result and impact of digital storytelling on student outcomes}

The production of digital stories capitalizes on the creative talents of students, and consequently they take great pride in the finished product and in seeing their efforts projected on a screen in front of their peers while engaging the entire class. In addition, student collaboration of digital production or peer editing of narrative text reveals moments of engagement, leadership, and students taking control. Furthermore, digital media production provides a meaningful vehicle for assessment. Overall, digital storytelling is a beneficial and valuable mechanism for improving the four-skill areas of English language competency. The digital resources allow teachers to create new techniques, as well as reevaluate and improve the more traditional techniques that help bring the target culture into the classroom.

The outcome of the experiment comprises thee aspects of English language proficiency:

Four-skill areas of English language proficiency

Basic knowledge of culture

Overall academic performance in English lessons

To have a complete picture of the positive and negative aspects of the implementation of digital storytelling in classroom setting these aspects were assessed respectively:

Four language skills test

Multiple choice test

Traditional first term marks

\section{The effects of digital storytelling on the four-skill areas of English language proficiency}

Post-test was prepared using pre-test structure (see table 1), thus, it consists of listening, reading, writing and speaking parts.

Table 1. The students' average performance based on the four language skill acquisition pretest and posttest.

\begin{tabular}{|c|c|c|c|c|c|c|c|}
\hline \multirow[t]{2}{*}{ Group } & \multirow[t]{2}{*}{ Skill } & \multirow[t]{2}{*}{ Max points } & \multicolumn{2}{|c|}{ Pre-testing } & \multicolumn{2}{|c|}{ Post-testing } & \multirow[t]{2}{*}{ Variance $\%$} \\
\hline & & & points & $\%$ & $\begin{array}{l}\text { point } \\
\mathrm{s}\end{array}$ & $\%$ & \\
\hline \multirow{4}{*}{$\begin{array}{l}\text { Control } \\
\text { "A" subgroup }\end{array}$} & Writing & 10 & 6.9 & $69 \%$ & 7.2 & $72 \%$ & $3 \%$ \\
\hline & Reading & 4 & 3 & $75 \%$ & 3.1 & $77.5 \%$ & $2.5 \%$ \\
\hline & Listening & 20 & 15.3 & $76.5 \%$ & 15.8 & $79 \%$ & $2.5 \%$ \\
\hline & Speaking & 15 & 9.7 & $64.7 \%$ & 10.2 & $68 \%$ & $3.3 \%$ \\
\hline \multirow{4}{*}{$\begin{array}{l}\text { Experimental } \\
\text { "B" subgroup }\end{array}$} & Writing & 10 & 5.1 & $51 \%$ & 6.3 & $63 \%$ & $12 \%$ \\
\hline & Reading & 4 & 1.5 & $37.5 \%$ & 2.1 & 52. $2 \%$ & $14.7 \%$ \\
\hline & Listening & 20 & 10.8 & $54 \%$ & 11.2 & $56 \%$ & $2 \%$ \\
\hline & Speaking & 15 & 8.4 & $56 \%$ & 9.6 & $64 \%$ & $8 \%$ \\
\hline
\end{tabular}

As the table 1 denotes there are differences between experimental and control groups regarding listening, speaking, reading and writing on pretests and posttests. The variance of the four-skill acquisition in the experimental group is much higher than in control. The highest positive deviation is observed regarding reading and writing skills, then speaking skill improvement is $8 \%$, which is higher than in control group. However, the least rise is showed regarding listening skill. Therefore, there is no significant correlation using a storytelling approach and effect on listening skill. The average variance 
of all the skills in the control group is $3 \%$. In comparison with the control group, the moderated average variance of the experimental group is $9 \%$. The results point out that all participants of the control group had made some improvements after the study but the improvement was not as big as the one made by the experimental group learners. The average variance of the experimental group was obviously superior to that of the control group, showing that the digital storytelling technique could effectively enhance the four-skills acquisition of the students.

According to the table, the average result of control group on the writing pretest was $69 \%$. Regarding the performance of experimental group on the writing pre-test percentage was $51 \%$. In addition, the control group's writing post-test was $72 \%$ with the variance of $3 \%$ and the outcome of experimental group on post-test writing was $63 \%$ with the variance of $12 \%$. Therefore, it can be concluded that the average performance of experimental group on the writing skill posttest increased $10 \%$ more compared to that of the control group.

Regarding the performance of control group on speaking pre-test and post-test, the resulting variance is $3.3 \%$. In addition, the variance of the experimental group on speaking is $8 \%$. Therefore, it can be concluded that the mean of experimental group on the post-test motivation increased more than that of the control group. The average performance of the experimental group raised by $9 \%$. These results are reflected in Figure 2 . Among the participants in the experimental group who were engaged in the digital storytelling project, stated that the application of digital storytelling leads to development of their speaking performance. They mostly had the following comments:

I like reading stories on the screen because it is interesting to me. Now telling stories is not a nightmare for me anymore.

When I take part in storytelling, I give my full attention to what others say. I learned something new about my classmates.

It was a great experience during my education. I have a great fear of public speaking, but now it seems that I can speak publicly with a long preparation.

Stories make me truly think about the topic. Now I have become more interested in history and cultural peculiarities of English speaking countries.

I like working with computer and look for information myself. I have learned a great deal about the ways of presenting stories.

I've always loved history of England and I am happy to have a choice of topics. Now I can share my passion with all my classmates.

Figure 2. The effects of digital storytelling on the four-skill areas of English language proficiency.

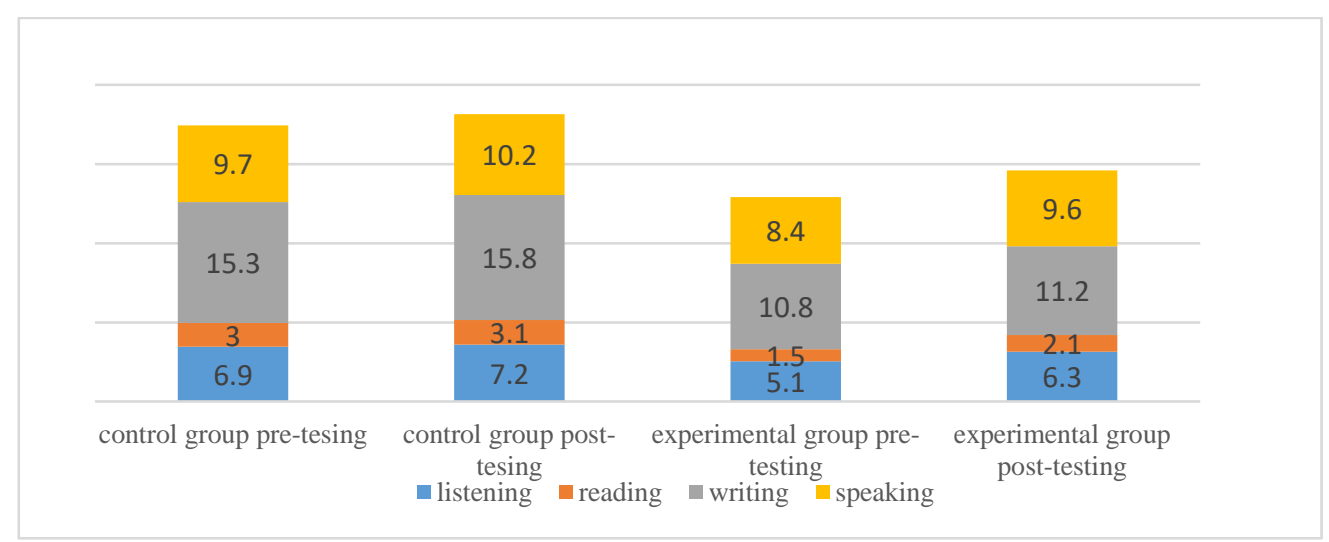

\section{The effects of digital storytelling on the basic knowledge of culture}

One of the main goals of the present study is to argue that DSt is utilized as a versatile tool to improve students' cultural knowledge in an EFL context. Here it has been illustrated how cultural context drives a digital storytelling project. Moreover it allows teachers to create new techniques as well as reevaluate and improve the more traditional techniques that help 
bring the target culture into the classroom. Research has shown that language learning should occur in a dynamic and active manner. Technology-based activities together with an inquiry learning approach allow students to interact directly with the second language and its culture without time and place restrictions and to explore and construct a deeper understanding of English language cultural knowledge. The digital storytelling serves as a dynamic learning environment that promotes an understanding of the intersection of culture and language in all aspects of cultural understandings, both tangible and intangible, and develops and improves strategies that are conducive for learning the cultural concepts.

The process was explored very urgent cultural issues that students had chosen beforehand with a particular purpose. The purpose impacted an opportunity to reflect different positions, attitudes, beliefs, and hopes on life and tried to find deep connections with subject-matter. To illustrate this research it was noticed the most favourite issues were: Clothes, Fears, Marriages, and Lifestyles. As the assessment of the cultural knowledge criteria, the participants of the both control and experimental groups were asked to complete a multiple-choice test consisting of 20 questions comprising all the material in the curriculum of the both groups. The students were purposefully given this survey at the end of the storytelling project in the hope that the results would show the effectiveness of digital storytelling experience.

Figure 3. The outcomes of the multiple-choice test on cultural knowledge

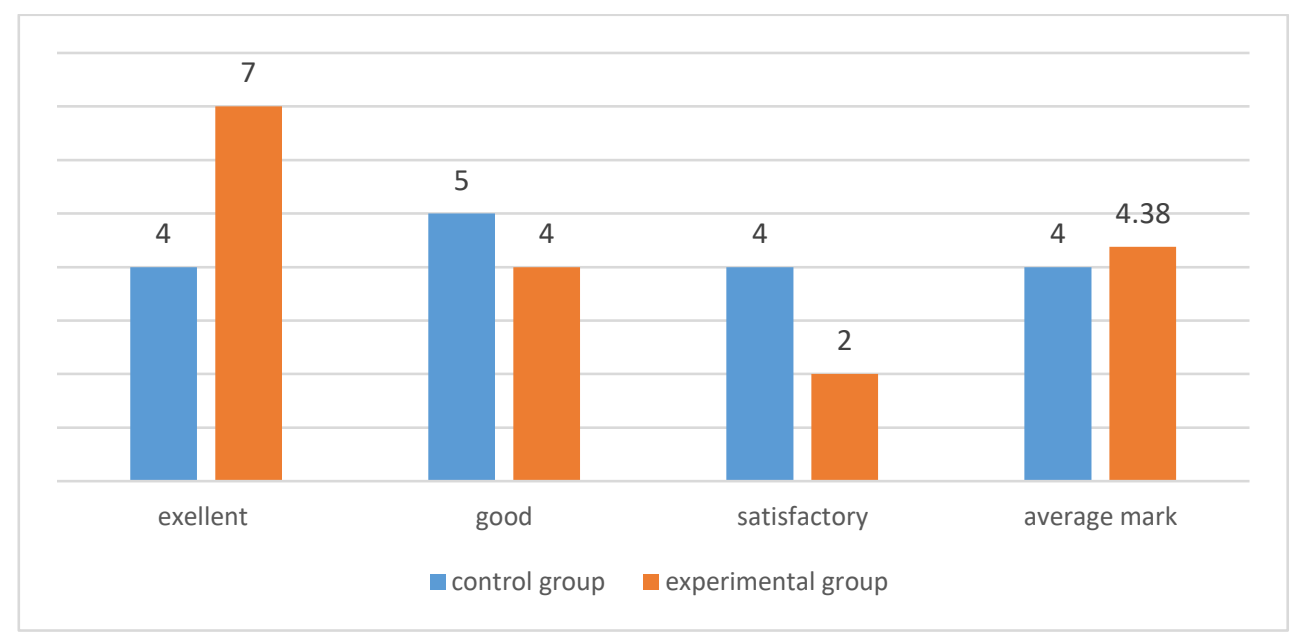

As Figure 3 illustrates the average score obtained on the culture-based test for the experimental group is 0.38 greater than the one for the control group. The number of excellent marks is greater in experimental group by 3 . At the same time number of the satisfactory marks in experimental group is less than in the one in control group by 2. Apparently, number of good marks in control group is greater than the one in experimental by 1 . The overall outcome of the culture-based test demonstrates the effectiveness of the digital storytelling technique for better comprehension and retention of the cultural information. The results demonstrate great improvement of the experimental group and advocate the digital storytelling technique as a powerful pedagogical tool in language classroom.

\section{The effects of digital storytelling on the overall academic performance in English lessons}

The usage of a new technique always affects all the spheres of the students' performance. The basic results of the experiment are measured using traditional grading system. The outcome of comparison between the performance of the previous academic term and the term in the course of which the experiment was held is reflected in Table 2 below.

Table 2. The performance of the students according to the traditional grading system.

\begin{tabular}{|l|l|l|l|l|}
\hline Group & Previous & \multicolumn{2}{c|}{ 1st term mark } \\
\cline { 2 - 4 } & $\begin{array}{l}\text { Number of } \\
\text { students }\end{array}$ & $\%$ & $\begin{array}{l}\text { Number } \\
\text { of } \\
\text { students }\end{array}$ \\
\hline
\end{tabular}




\begin{tabular}{|l|l|l|l|l|l|l|}
\hline \multirow{2}{*}{$\begin{array}{l}\text { Control "A" } \\
\text { subgroup }\end{array}$} & excellent & $31 \%$ & 4 & $31 \%$ & 4 & $0 \%$ \\
\cline { 2 - 7 } & good & $46 \%$ & 6 & $46 \%$ & 6 & $0 \%$ \\
\cline { 2 - 7 } & satisfactory & $23 \%$ & 3 & $23 \%$ & 3 & $0 \%$ \\
\cline { 2 - 7 } & unsatisfactory & $0 \%$ & 0 & $0 \%$ & 0 & $0 \%$ \\
\hline \multirow{3}{*}{$\begin{array}{l}\text { Experimental "B" } \\
\text { subgroup }\end{array}$} & excellent & $23 \%$ & 3 & $23 \%$ & 3 & $0 \%$ \\
\cline { 2 - 7 } & good & $31 \%$ & 4 & $38.3 \%$ & 5 & $7.3 \%$ \\
\cline { 2 - 7 } & Satisfactory & $31 \%$ & 4 & $31 \%$ & 4 & $0 \%$ \\
\cline { 2 - 7 } & unsatisfactory & $15 \%$ & 2 & $7.7 \%$ & 1 & $7.3 \%$ \\
\hline
\end{tabular}

As the Table 2 illustrates the performance of the student from control group did not change and number of the students possessing particular mark stayed the same. Conversely, the experimental group's results slightly differentiate from the previous ones. To be precise, the number of students obtained good mark is increased by 1 , in the same time the number of the students possessing unsatisfactory mark is decreased by 1 . The number of the students having satisfactory mark did not change, but one of the student improved his mark to good, and another one replaced him by improving his result from unsatisfactory to satisfactory mark. Such outcome clearly shows improvement in language proficiency and proves the effectiveness of the digital storytelling in English language classroom. The diversification of the student's English language acquisition is depicted in the Figure 4.

Figure 4. The discrepancy in mark according to the traditional grading system

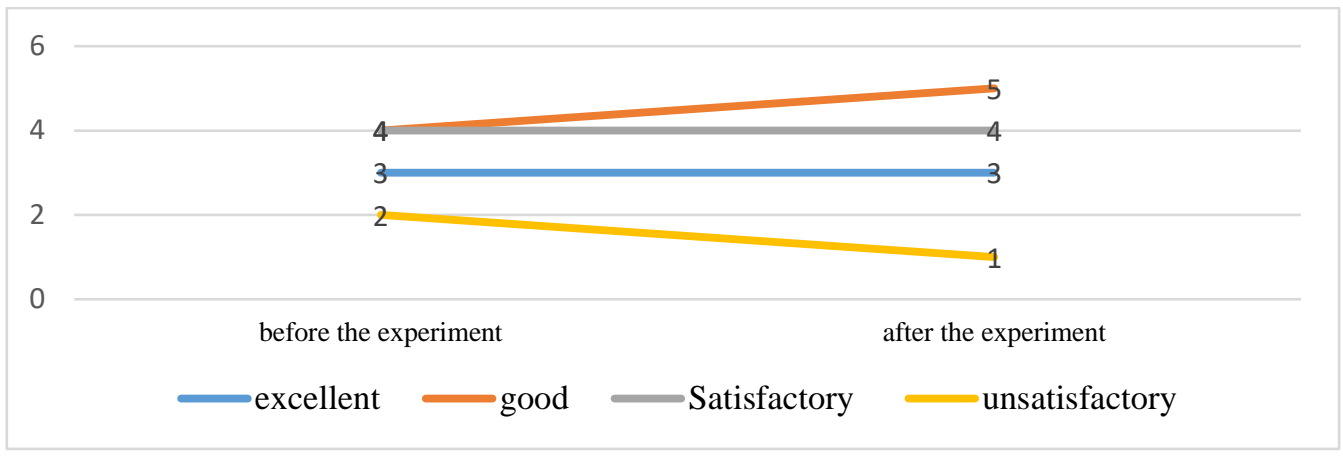

Taking the findings of this study into account, it can be claimed that technology of digital story telling brings about new ways of thinking about and organizing materials and as a result increases students' performance. It can be considered as an effective tool for improving learners' average performance as it involves students in learning process. Learners not only become more interested in their learning but also take more responsibility for their learning.

The experiment in the language classroom revealed that students respond to such a learning experience. Teaching experiment was chosen since the point of interest was raising interest to the culture and not the learning result alone. It was found that there is a positive interaction in line with the original goals set, among students and with their teacher as well during the digital story development process. Furthermore, it was found that learners are motivated and engaged in the activities within the learning context that combines materials and experiential activities along with new tools.

As far as the research assumptions are concerned, it was verified that digital storytelling development encourages interaction between students and the teacher as well and enhance academic performance of the students. Digital storytelling boosted learners' confidence enhanced cooperation and revealed possibilities that could never emerge through traditional activities. Students not only managed to make their own digital story but they animated it with their personal way of expression. It is highlighted that the teacher in this process provides the "spark" and tools and helps students using them, but at every stage of the process it is learners themselves that give meaning to what they create. DSt is one pedagogical tool that should be used in language classrooms. Perhaps by utilizing digital storytelling in education researchers will arrive at a deeper understanding of the different and more powerful roles that digital media can play in both teaching and learning

\section{Findings}


The digital resources allow teachers to create new techniques as well as reevaluate and improve the more traditional techniques that help bring the target culture into the classroom. Since the main aim of this research was to investigate the peculiarities of digital stories and prove experimentally the effectiveness of using this technological tool as DSt in cultural diversity while teaching a foreign language. This study contributes to new understandings of how to create authentic cultural learning context that can be used in a range of educational settings. The research focused on how to implement digital storytelling in the classroom, describing the digital story workshop, and explaining teacher roles and student tasks; therefore, this research gives a clear picture of how to integrate digital storytelling into Kazakhstani schools. Consequently, the new knowledge generated by this research can be implemented corresponding future educational policy. Firstly, in the practical part it was presented the results of the pre-test in both control and experimental groups. Secondly, the sequence of workshops plans on cultural topics were generated using models have been created in the past to help educators achieve better learning outcomes with digital storytelling and probed experimentally. Thirdly, the post-test was held and the findings indicate that the learners in the experimental group, initially having inferior results, noticeably improved performance according to traditional grading system and four-skill language acquisition; the students in the control group have showed practically the same results as in pre-test. As a result DSt significantly improves students' speaking, listening and reading skills much more than the traditional way of teaching. However, the effectiveness of digital stories in relation to writing skill did not show its effectiveness. In regard to culture knowledge the students of the experimental group outperformed the ones in the control group. Thus, the experimental results of students' performance conform digital storytelling approach can engage students in the practical environment. Digital storytelling makes practice and training more engaging, diverse, and customized to their needs and challenges.

Through the process of digital storytelling, students can turn narratives into multimedia productions to develop reading, writing, listening and speaking skills. The technique of digital storytelling can be used effectively in Kazakhstani classroom setting to improve cultural and academic acquisition. As seen above, the experimental class outperformed the other one in cultural knowledge. They presented stories using digital images, photographs, video, animation, sound, music, text and a narrative voice boosted the positive motivating impression of storytelling and enabled students to construct compelling and creative narratives of the story. Simply put, by involving DSt not only learning becomes personal, enjoyable, attractive and creative but it helps students improve their reading, listening and speaking skills in the context of target culture by learning to express opinions and constructing digital narratives for an audience.

\section{References}

[1] Tomalin, B. (2006) Understand a new culture ... yourself. Learning English. March 10 - P. 5

[2] Kramsch C. (2001) Language, culture and voice in the teaching of English as a foreign language. Language Issues. №13. - pp. 2-7

[3] Tomalin B. \& Stempleski S. (1993) Cultural awareness. - Oxford University Press. -Oxford. - 168 p.

[4] Byram, M. (2002) Developing The Intercultural Dimension in Language Teaching. -Council of Europe. Strasburg. - $42 \mathrm{p}$.

[5] Brenner K. (2014) Digital Stories: A 21st-Century Communication Tool for the English Language Classroom/l English Teaching Forum. - №1. - pp. 22-29

[6] Barrett H. Researching and evaluating digital storytelling as a deep learning tool// Proceedings of Society for Information Technology and Teacher Education International Conference 2006. - pp. 647-654

[7] Dudeney, G., Hockly, N., \& Pegrum, M. (2014): Digital Literacies. Book. Routledge.

[8] Miller, E. (2009) Digital Storytelling, in Department of Curriculum and Instruction. - University of Northern lowa. - lowa. - $35 \mathrm{p}$.

[9] Galac, A. (2011) Engaging Hearts and Minds: Using Digital Storytelling in High School ELA Classes to Prepare Students for the 21st Century. University of Victoria. - p. 103-109 